Tropical Journal of Pharmaceutical Research January 2021; 20 (1): 177-182

ISSN: $1596-5996$ (print); 1596-9827 (electronic) (C) Pharmacotherapy Group, Faculty of Pharmacy, University of Benin, Benin City, 300001 Nigeria.

\title{
Assessment of the relationship between depression and treatment compliance in chronically-ill patients in Jeddah, Saudi Arabia
}

\author{
Ameen Mosleh Almohammadi, Somayah Saeed Bawazeer, Joud Jamal \\ Balkhair, Aroub Adel Rajab \\ Department of Pharmacy Practice, Faculty of Pharmacy, King Abdulaziz University, PO Box 80260, Jeddah 21589, Saudi \\ Arabia \\ *For correspondence: Email: yahmadi@taibahu.edu.sa; Tel: +966-504378234, +966-126400000 ext 20675
}

Sent for review: 24 May 2020

Revised accepted: 23 December 2020

\begin{abstract}
Purpose: To find the relationship between depression, treatment adherence and lifestyle changes in chronically-ill patients residing in Jeddah, Saudi Arabia.

Methods: A cross-sectional study was conducted. A self-administered questionnaire was used to collect data from patients of multi-healthcare centers located in Jeddah. The questionnaire aimed to collect the information regarding patients' levels of medication compliance, patients' capacity to cope with the disease and adherence to medication, along with their depression level.

Results: Of the overall sample size of 439 patients, $43.1 \%$ were suffering from hypertension, $37.8 \%$ were diabetic and $33.7 \%$ had hyperlipidemia. Besides, total scores of Patient Health Questionnaire-9 (PHQ-9) showed that approximately $5 \%$ patients were severely depressed, $8 \%$ had moderately severe depression, $27 \%$ had moderate depression, and $60 \%$ had mild depression. Compliance scale data revealed that $38 \%$ patients showed low compliance, $51 \%$ showed partial compliance, and $11 \%$ showed high compliance. Also, a significant inverse relationship between depression and compliance scales ( $r s=-0.221, p=0.004$ ) was observed.

Conclusion: The results show an inverse association between depression and medication adherence in patients with chronic disease in Jeddah. Therefore, clinicians are advised to assess the level of depression in chronically-ill patients in order to improve their adherence to medicine.
\end{abstract}

Keywords: Chronic illness, Depression, Medication adherence, Treatment compliance

\begin{abstract}
This is an Open Access article that uses a fund-ing model which does not charge readers or their institutions for access and distributed under the terms of the Creative Commons Attribution License (http://creativecommons.org/licenses/by/4.0) and the Budapest Open Access Initiative (http://www.budapestopenaccessinitiative.org/read), which permit unrestricted use, distribution, and reproduction in any medium, provided the original work is properly credited.

Tropical Journal of Pharmaceutical Research is indexed by Science Citation Index (SciSearch), Scopus, International Pharmaceutical Abstract, Chemical Abstracts, Embase, Index Copernicus, EBSCO, African Index Medicus, JournalSeek, Journal Citation Reports/Science Edition, Directory of Open Access Journals (DOAJ), African Journal Online, Bioline International, Open-J-Gate and Pharmacy Abstracts
\end{abstract}

\section{INTRODUCTION}

Chronic diseases are likely to be managed through medications; however, in certain cases the approach to enhance adherence to long-term therapy remains poor [1]. According to the data obtained from the Middle Eastern countries, patients' adherence to medication ranges between $1.4 \%$ to $88 \%$ which corresponded to the methods used for assessing and quantifying the adherence [2]. Certain factors such as; patient's knowledge about a disease, beliefs related to medications, the large gap from therapeutic goals, perception of self-expertise, 
and attitude towards a disease play a significant role in influencing patient's adherence to medication [3].

Notably, individuals suffering from multiple comorbid conditions such as depression tend to show increased adherence to statins [4]. Seo et al [5] defined depression as a state of a persistent feeling of sadness and loss of interest, which is considered as a mental illness. Several studies have shown that in most cases, comorbid depression results in minimal or no use of medicine along with patient's non-compliance to treatment [6-7]. It may also result in costly hospital admissions, which may be based on preventable events, and loss of productivity due to illness [8].

The initial period of treatment is specifically critical to ensure patient's adherence to treatment and is associated with the increased risks of relapse, medication discontinuation, high economic burden, vulnerability to suicide, and treatment dropout even though nonadherence is challenging within the treatment [9]. Since patient's adherence to medication and early appropriate antidepressant dosing are useful in patient's recovery from depression, they are effective in enhancing the long-term consequences of patients with depression.

Patient's negative attitude serve as the major factor that influence adherence to medication and treatment. As in the case of older adults, certain challenges such as distance from home to physician's office and cost of medications hinder the treatment process, still treatment discontinuation and poorer medication adherence among older adults with depression is highly predicted by perceived stigma [10]. Poor adherence is further due to low perceived symptom severity and; therefore, many older adults do not seek mental health help even when distress is comprehended [11]. Nonadherent behaviors are more likely to result when perceived costs outweigh perceived benefits [12].

Patient's compliance to medication is gaining much acknowledgment as an area of research with a persistent increase in the prevalence of chronic diseases. Most of these studies have been conducted in developed countries while there is no sufficient evidence on the subject. The extensive literature on medication compliance in Saudi Arabia has mostly emphasized on few chronic diseases such as diabetes, hypertension, obesity, and low levels of vitamin- $D$, while other chronic conditions such as hyperlipidemia, heart diseases, osteoporosis, thyroid disease, and rheumatoid arthritis have not been much explored. On this premise, this study sought to identify the relationship between depression and adherence to management and lifestyle changes among chronically ill patients in Jeddah population.

\section{METHODS}

\section{Study design and population}

The current study followed a cross-sectional study design and was conducted in multi healthcare centers located in Jeddah. The overall duration to conduct this study was two months, while International guidelines for human studies as stated by International Ethical Guidelines for Health-related Research Involving Humans were followed [13]. The Research Ethics Committee, Faculty of Medicine, Jeddah approved this study (approval no. D/39/89927).

The study population included patients with the following characteristics; a) patients who were native Arabic speakers, b) patients aged above 15 years c) patients suffering from a chronic illness which requires life time use of medicines. A total of 502 patients were recruited in this regard. Patients were directed to have a brief overview of the study. 63 patients declined participating in the study due to time limitation, leaving 439 patients to be included in statistical analysis. A written consent was signed by participants after confirming their participation. The confirmed participants were assured of the confidentiality of the information they provided and guided by research assistance about how to complete the questionnaire.

Data on patient's chronic illnesses such as; hypertension, diabetes mellitus, asthma, hyperlipidemia, heart diseases, osteoporosis, thyroid disease, rheumatoid arthritis, and other diseases that require life-time use of medication were recorded. Demographic data including age, gender, nationality, education, number of chronic diseases, duration of illness, and chronic disease were also noted.

\section{Treatment tool and parameters}

The Patient Health Questionnaire (PHQ-9) was used as a tool to assess depression in patients. It is considered an adequate and reliable tool for self-administration. The responses were recorded on Likert scale ranging between 0 and 3 . The obtained scores were added to produce a total score ranging from $0-27$. The higher scores indicated greater depressive symptoms. The scores greater than $5,10,15$, or 20 refer to 
mild, moderate, moderately severe or severe depression, respectively [14].

The evaluation of medication adherence was performed based on five categories including diet-related adherence, exercise-related adherence, medicine-related adherence, measurement-related adherence, and smokingrelated adherence. It consists of one general scale that was numbered according to the level of medication compliance from 1 - 5 (1 = noncompliance and 5 = fully compliance). The benefit of this scale is to let the patient generally report his/her level of compliance, followed by 8 items designed to assess the extent of adherence to treatment, food, and lifestyle. Patient's level of compliance was assessed following the score break up criteria, where patients who scored between 24-20 indicated high level of compliance, while those scored between 19-13 and 12-8 indicated partial and low compliance respectively.

\section{Statistical analysis}

The data were coded and analyzed using SPSS. The differences between patients' demographics, type and number of the disease, duration of illness, and a number of medications were calculated through nonparametric analysis tests such as Mann-Whitney and Kruskal-Wallis. Spearman's Correlation test was used to find the associations that may exist between the outcome's measures of the study. The significance level was set at $p<0.05$. The reliability of the study tool was checked through Cronbach's alpha test.

\section{RESULTS}

The study results showed that 288 (65.6\%) patients were female and $151(34.4 \%)$ of them were male. The complete demographic profile of the respondents is presented in Table 1. It shows that $43.1 \%$ of the study patients were diagnosed with hypertension, $37.8 \%$ complained of diabetes, and $33.7 \%$ had hyperlipidemia.

The patient's responses to the overall questionnaire's items showed internal consistency reliability measured by Cronbach's $\alpha$ $=0.71$. The Cronbach test showed that the 9 items of $\mathrm{PHQ}$ showed very good reliability $(\alpha=$ 0.85); whereas, 8 items of compliance showed a moderate reliability when tested by Cronbach's $(\alpha=0.67)$. Total scores of PHQ-9 showed that 22 (5\%) patients were having severe depression, 35 (8 \%) had moderate to severe depression, $119(27 \%)$ had moderate depression, and 263 (60 \%) had mild depression (Table 1). The results further showed that female patients scored higher on depression scale than male patients with significant differences $(P=0.037)$.

Table 1: Demographic profile of the respondents

\begin{tabular}{|c|c|c|c|}
\hline Variable & & $\mathbf{N}$ & $\%$ \\
\hline \multirow{2}{*}{ Sex } & Male & 151 & 34.4 \\
\hline & Female & 288 & 65.6 \\
\hline \multirow[t]{3}{*}{ Age } & $<30$ & 75 & 17.1 \\
\hline & $31-60$ & 317 & 72.2 \\
\hline & $>61$ & 47 & 10.7 \\
\hline \multirow[t]{2}{*}{ Nationality } & Saudi & 339 & 77.2 \\
\hline & Non-Saudi & 100 & 22.8 \\
\hline \multirow[t]{3}{*}{$\begin{array}{l}\text { Educational } \\
\text { level }\end{array}$} & $\begin{array}{l}\text { Less than high } \\
\text { school }\end{array}$ & 108 & 24.6 \\
\hline & High school & 120 & 27.3 \\
\hline & $\begin{array}{l}\text { University and } \\
\text { above }\end{array}$ & 211 & 48.1 \\
\hline \multirow{4}{*}{$\begin{array}{l}\text { Number of } \\
\text { chronic } \\
\text { diseases }\end{array}$} & 1 disease & 207 & 47.2 \\
\hline & 2 diseases & 97 & 22.1 \\
\hline & 3 diseases & 76 & 17.3 \\
\hline & $>3$ diseases & 59 & 13.4 \\
\hline \multirow{3}{*}{$\begin{array}{l}\text { Duration of } \\
\text { illness }\end{array}$} & $<6$ months & 36 & 8.2 \\
\hline & 6-24 months & 75 & 17.1 \\
\hline & $>24$ months & 328 & 74.7 \\
\hline Chronic & Hypertension & 189 & 43.1 \\
\hline \multirow[t]{9}{*}{ Disease } & DM & 166 & 37.8 \\
\hline & Hyperlipidemia & 148 & 33.7 \\
\hline & Heart Diseases & 74 & 16.9 \\
\hline & Osteoporosis & 78 & 17.8 \\
\hline & Thyroid & 85 & 19.4 \\
\hline & Rheumatoid & 39 & 8.9 \\
\hline & Arthritis & & \\
\hline & Asthma & 51 & 11.6 \\
\hline & Others & 64 & 14.6 \\
\hline \multirow[t]{4}{*}{ Depression } & Mild & 263 & 60 \\
\hline & Moderate & 119 & 27 \\
\hline & $\begin{array}{l}\text { Moderately } \\
\text { severe }\end{array}$ & 35 & 8 \\
\hline & Severe & 22 & 5 \\
\hline \multirow[t]{3}{*}{ Adherence } & Low compliance & 166 & 38 \\
\hline & $\begin{array}{l}\text { Partial } \\
\text { compliance }\end{array}$ & 224 & 51 \\
\hline & High compliance & 49 & 11 \\
\hline
\end{tabular}

Moreover, patients suffering from thyroid disease $(P=0.014)$ and those with osteoporosis $(p=$ 0.003 ) scored higher on the depression scale, as compared to other types of chronic diseases. However, there was no difference in depression score with respect to nationality, educational level, and age, duration of illness, number of chronic diseases, and number of medications used. Results of the compliance scale showed that $166(38 \%)$ patients had low compliance level, while $224(51 \%)$ and $49(11 \%)$ showed partial and high compliance respectively (Table 1).

In statistical analysis, patients who showed higher compliance were older than 60 years $(P=$ $0.003)$, suffering from the chronic disease more than 2 years $(P=0.038)$, and taking more than 6 
medications $(P=0.012)$. According to the type of the disease, there was no significant difference in compliance scale except for patients with diabetes mellitus who showed higher compliance $(P=0.038)$. Rheumatoid Arthritis showed lower compliance $(P=0.038)$, as compared to other diseases. Interestingly, analysis of the results showed that Saudi patients reported lower compliance total score, as compared to nonSaudi patients $(P=0.004)$. However, there was no difference in compliance according to sex, educational level, number of chronic diseases, and type of the disease. Patients who rated themselves as low or non-compliant in the general adherence question received lower compliance total score $(P<0.001)$ (Figure 1). There was a significant inverse relationship between compliance scales and depression $\left(r_{s}=\right.$ $-0.221, p=0.004)$.

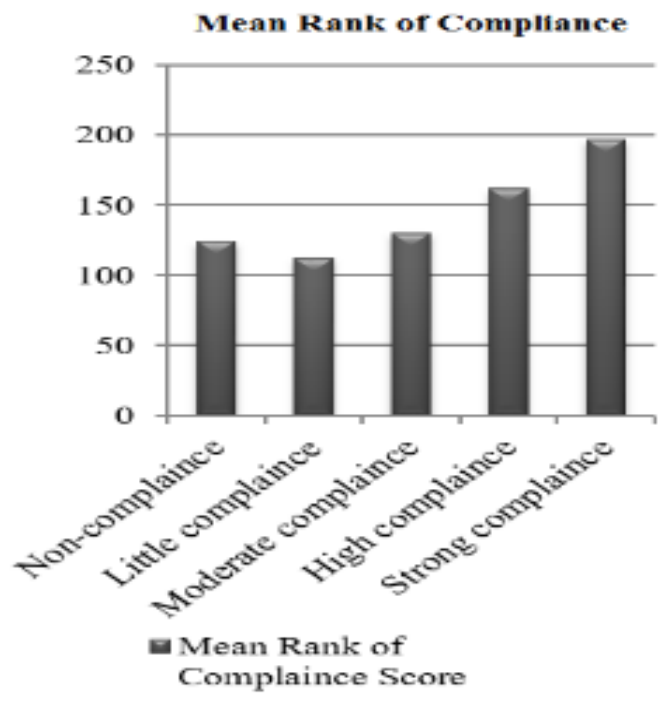

Figure 1: Mean rank of compliance score

\section{DISCUSSION}

The results of the present study have shown an inverse relationship between depression and medication adherence in chronically ill patients in Jeddah, Saudi Arabia. Patients who were classified as non-depressed, scored higher in compliance scale in comparison with patients who were severely depressed. This is completely in agreement with several studies, which investigated this relationship between depression and compliance in other countries. For instance, a meta-analysis conducted by Gernard et al [14] included 31 studies, with 18,245 participants showed a statistically significant relationship between depression and treatment compliance. Additionally, the study also revealed that patients suffering from hypertension or hyperlipidemia with depression were non-adherent as those with diabetes. The type of chronic disease in this study was also found to have an effect on patients' total scores of depression such as those patients with thyroid disease and those with osteoporosis reported higher depression scores than those of other types of chronic diseases. In the present study, the PHQ-9 test represented the last 14 days of a patient's life and stated that it needs to be repeated every two weeks to diagnose depression state.

A similar study conducted by Lemay et al [15] showed that there is a significant negative impact of beliefs towards medication on its adherence among chronically ill patients. This result was also supported by the present study. This clearly depicts that negative beliefs about medication contribute to suboptimal adherence towards medication as a significant predictor. Al-Foraih and Somerset [16] showed that less adherence to medicines was found in patients that were not severely ill, in comparison to the older patients suffering from several comorbid conditions as they are more concerned with the treatment regimen as they are aware of their own mortality.

The present study has shown no difference in the level of compliance with respect to sex, education level, number of chronic diseases, and type of the disease. However, a study conducted by Lemay et al [15] indicated that patients with lower education levels and higher illness severity were more likely to have negative beliefs about medications. Moreover, the impact of nationality on medication adherence explained that there is a significant influence of cultural background on patients' beliefs about medication [15]. The current study showed that about one-third of patients showed good compliance and adherence towards medication. However, a recent study conducted by Acar and Gunes [17] showed that $50.8 \%$ of the patients used their medicines regularly and their adherence to drug treatment was better than their adherence to diet and fluid restriction. The results of the present study showed satisfactory results related to patients' understanding of the disease, treatment benefit, and their adherence to medicine.

\section{Limitations of the study}

The study results are limited as the data did not include whether the patient was taking any antidepressant medication or psychiatric drugs. Future studies need to focus on the quality of life of the patients suffering from osteoporosis and asthma. Moreover, such studies also need to investigate the impact of taking antidepressant medication or psychiatric drugs. 


\section{CONCLUSION}

The present study investigated the relationship between depression and treatment adherence among chronically ill patients in Jeddah. It indicates an inverse association between depression and medication compliance among them. Therefore, clinicians are encouraged to assess the status of depression in chronically illpatients to improve their adherence.

\section{DECLARATIONS}

\section{Acknowledgement}

This work was supported by the Deanship of Scientific Research (DSR), King Abdul-Aziz, University, Jeddah, under grant no. 166 - 125 D1440. The authors, therefore, gratefully acknowledge the DSR technical and financial support. Special thanks to the patients who participated in this study.

\section{Conflict of interest}

No conflict of interest is associated with this work.

\section{Contribution of authors}

We declare that this work was done by the authors named in this article and all liabilities pertaining to claims relating to the content of this article will be borne by the authors.

\section{Open Access}

This is an Open Access article that uses a funding model which does not charge readers or their institutions for access and distributed under the terms of the Creative Commons Attribution License (http://creativecommons.org/licenses/by/ 4.0) and the Budapest Open Access Initiative (http://www.budapestopenaccessinitiative.org/rea d), which permit unrestricted use, distribution, and reproduction in any medium, provided the original work is properly credited.

\section{REFERENCES}

1. Bansilal S, Castellano JM, Garrido E, Wei HG, Freeman A, Spettell C, Garcia-Alonso F, Lizano I, Arnold RJ, Rajda J. Assessing the impact of medication adherence on long-term cardiovascular outcomes. J Am Coll Cardiol 2016; 68(8): 789-801. https://doi.org/10.1016/ j.jacc.2016.06.005

2. Al Qasem A, Smith F, Clifford S. Adherence to medication among chronic patients in Middle Eastern countries: review of studies. EMHJ 2011; 17(4): 356363.https://doi.org/10.1159/000450644

3. Jeragh-Alhaddad FB, Waheedi M, Barber ND, Brock TP. Barriers to medication taking among Kuwaiti patients with type 2 diabetes: a qualitative study. Patient Prefer Adherence 2015; 9: 1491. https://doi.org/10.2147/ ppa.s86719

4. Carter P, Al-Saffar N, Deshmukh A, Eid S. Health beliefs and drug compliance of depressed patients in Kuwait. $J$ Soc Adm Pharm 2003; 20: 142-150. https://doi.org/ 10.1211/0022357056181

5. Seo J, Choi B, Kim S, Lee H, Oh D. The relationship between multiple chronic diseases and depressive symptoms among middle-aged and elderly populations: results of a 2009 korean community health survey of 156,747 participants. BMC public health 2017; 17(1): 844-854. https://doi.org/10.1186/s12889-017-4798-2

6. Rosenthal Asher D, Ver Halen N, Cukor D. Depression and nonadherence predict mortality in hemodialysis treated end-stage renal disease patients. Hemodialysis International 2012; 16(3): 387-393. https://doi.org/ 10.1111/j.1542-4758.2012.00688.x

7. Sjösten $N$, Nabi $H$, Westerlund $H$, Salo $P$, Oksanen $T$, Pentti J, Virtanen M, Kivimäki M, Vahtera J. Effect of depression onset on adherence to medication among hypertensive patients: a longitudinal modelling study. J Hypertens 2013; 31(7): 1477-1484. https://doi.org/ 10.1097/ hjh.0b013e32836098d1

8. De Freitas GR, Tramontina MY, Balbinotto G, Hughes $D A$, Heineck I. Economic impact of emergency visits due to drug-related morbidity on a Brazilian hospital. Value Health Reg Issues 2017; 14: 1-8. https://doi.org/10.1016/j.vhri.2017.03.003

9. Pompili M, Venturini $P$, Palermo M, Stefani $H$, Seretti ME, Lamis DA, Serafini G, Amore M, Girardi P. Mood disorders medications: predictors of nonadherence: review of the current literature. Expert Rev Neurother 2013; 13(7): 809-825.

10. Sirey JA, Franklin AJ, McKenzie SE, Ghosh S, Raue PJ. Race, stigma, and mental health referrals among clients of aging services who screened positive for depression. Psychiatr Serv 2014; 65(4): 537-540.

11. Spoont MR, Nelson DB, Murdoch M, Rector T, Sayer NA, Nugent S, Westermeyer J. Impact of treatment beliefs and social network encouragement on initiation of care by VA service users with PTSD. Psychiatr Serv 2014; 65(5): 654-662.

12. Brenes GA, Danhauer SC, Lyles MF, Hogan PE, Miller ME. Barriers to mental health treatment in rural older adults. Am J Geriatr Psychiatry 2015; 23(11): 11721178.

13. Kroenke K, Spitzer RL. The PHQ-9: A new depression diagnostic and severity measure. Psychiatric Annals 2002; 32(9): 1-7.

14. Grenard JL, Munjas BA, Adams JL, Suttorp M, Maglione M, McGlynn EA, Gellad WF. Depression and medication adherence in the treatment of chronic diseases in the United States: a meta-analysis. J Gen Intern Med 2011;

Trop J Pharm Res, January 2021; 20(1): 181 
26(10): 1175-1182. https://doi.org/10.1007/s11606-011$1704-y$

15. Lemay J, Waheedi M, Al-Sharqawi S, Bayoud $T$. Medication adherence in chronic illness: do beliefs about medications play a role? Patient Prefer Adherence.2018; 12: 1687-1698. https://doi.org/10. 2147/ppa.s169236
16. Al-Foraih $M$, Somerset S. Factors affecting adherence to statins in hypercholesterolemic Kuwaiti patients: a cross-sectional study. Medical Principles and Practice 2017; 26(1): 35-40.

17. Acar D, Güneş Z. Factors affecting therapeutic compliance in patients with chronic renal failure: Anxiety, Depression, IIlness Perception. Age 2018; 61: 14-19. https://doi.org/10.15761/hpc.1000137. 